\title{
OS NOVOS PARADIGMAS DA MEDIAÇÃO ON-LINE
}

\author{
THE NEW PARADIGMS OF ONLINE MEDIATION
}

\section{Rosalina Moitta Pinto da Costa}

Doutora em Direito das Relações Sociais (PUC/SP). Mestre em Direito Agrário (UFPA). Especialista em Direito Ambiental (UFPA). Especialista em Direito Civil e Processo Civil (ESMPA). Professora de Direito Processual Civil da Universidade Federal do Pará (UFPA). Professora Permanente do Programa de Pós-Graduação Stricto Sensu em Direito da Universidade Federal do Pará (PPGD-UFPA).

E-mail: rosalina.costa@hotmail.com

Recebido em: 17/04/2020

Aprovado em: 05/04/2021

RESUMO: Esta pesquisa tem por objetivo analisar os novos paradigmas da mediação on-line em razão da introdução, no ambiente digital, de um quarto elemento, que é a tecnologia de comunicação e informação, a qual, alterando as formas de comunicação entre as partes e o mediador, exige uma adaptação da atividade e dos princípios da mediação tradicional à nova interação que ocorre entre os sujeitos. Utilizando-se o método dedutivo e a pesquisa bibliográfica como opção metodológica, parte-se da definição da mediação em ambiente on-line, estabelecendose seus limites e parâmetros, como método de solução de conflitos, entre os modos de resolução de disputa on-line (ODR). A seguir, apontando-se as vantagens, desvantagens e novas formas de interação da mediação on-line, problematizam-se os contornos que assume a mediação com o advento da tecnologia, questionando-se o novo viés que toma a mediação na era digital. Após analisar-se os princípios da mediação on-line à luz dos novos arquétipos introduzidos na era digital pelo quarto elemento, conclui-se que a mudança de paradigma da mediação on-line importa em alteração não na sua acepção, mas na natureza da interação e nas habilidades necessárias para gerenciar a comunicação e a troca de informações entre as partes e os mediadores, exigindo, sobretudo, mudança nas relações e habilidades do mediador.

Palavras-chave: Mediação on-line. Modos de resolução de disputa on-line. Confidencialidade. Autonomia da vontade das partes. Isonomia das partes.

ABSTRACT: This research aims at analyzing the new paradigms of online mediation due to the introduction, in the digital environment, of a four element, which is communication and information technology, which, by changing the forms of communication between the parties and the mediator, requires an adaptation of the activity and principles of traditional mediation to the new interaction that occurs between its subjects. Using the deductive method and bibliographic research as a methodological option, we start with the definition of mediation in an online environment, establishing its limits and parameters, as a method of conflict resolution, between online dispute resolution (ODR). Next, pointing out the advantages, disadvantages and new forms of interaction of online mediation, the contours that the mediation assumes with the advent of technology are being questioned, raising questions about the new bias that takes the mediation in 
the digital era. After analyzing the principles of online mediation in the light of the new archetypes introduced by the fourth element in the digital age, it is concluded that the paradigm shift in online mediation implies changes in the nature of interaction and in the skills needed to manage the communication and exchange of information between the parties and mediators; above all, it requires a change in the mediator's relationships and ability.

Keywords: Online mediation. Online dispute resolution modes. Confidentiality. Autonomy of the will of the parties. Isonomy of the parties.

SUMÁRIO: Introdução. 1 A mediação no ambiente digital. 1.1 Modos de resolução de disputa on-line. $1.2 \mathrm{O}$ que é mediação on-line? 2 Novos contornos da mediação com o advento do quarto elemento. 3 Os princípios da mediação on-line: Uma análise à luz do quarto elemento. 3.1 Confidencialidade. 3.2 Autonomia da vontade das partes. 3.3 Isonomia das partes. 3.4 Oralidade. 3.5 Informalidade. 3.6 Imparcialidade. 4 Os novos paradigmas da mediação on-line. Conclusão. Referências.

\section{INTRODUÇÃO}

A tecnologia está cada vez mais inserida na vida das pessoas e, ao contrário do que possa parecer, não provoca o isolamento dos seres humanos, mas apenas estabelece novas formas de conexão entre eles. De fato, ela simplesmente muda a forma como as pessoas interagem entre si, unindo-as de maneira diferente (RAINEY, 2014, p. 39).

Como a tecnologia de comunicação anterior (o telefone, a televisão, etc.), a tecnologia da informação e comunicação não eliminou, mas apenas mudou nossa interação social. Sente-se hoje a mesma preocupação de gerações atrás, quando surgiu o automóvel e a TV. Os temores de que as novas tecnologias de então acabariam com a sociabilidade não se concretizaram, porque nenhuma dessas tecnologias isolou-nos. Do mesmo modo, a tecnologia da informação e comunicação acaba sendo incorporada à vida das pessoas mais do que elas possam perceber. "As pessoas não estão ligadas nos aparelhos - estão ligadas entre si” ${ }^{1}$ (RAINIE; WELLMAN, 2012, p. 6).

As novas tecnologias mudam a maneira como fazemos coisas, por exemplo, como compramos, como nos comunicamos. Consequentemente, trazendo uma nova mentalidade, precisam de um processo também novo para a resolução dos conflitos, o que significa não apenas novas ferramentas, mas também diferentes princípios e valores (RABINOVICH-EINY; KATSH, 2014, p. 5).

Esta pesquisa tem por objetivo analisar os novos paradigmas da mediação on-line em razão da introdução, no ambiente digital, de um quarto elemento, que é a tecnologia de comunicação e informação, a qual, alterando as formas de comunicação entre as partes e o mediador, exige uma adaptação da atividade e dos princípios da mediação tradicional à nova interação que ocorre entre os sujeitos.

Para tanto, utilizando-se do método dedutivo e da pesquisa bibliográfica como opção metodológica, inicia-se o estudo discorrendo sobre os modos de resolução de litígios on-line (em inglês, online dispute resolution (ODR)), delimitando os mecanismos de solução de conflitos que podem ser abordados via on-line, para então conceituar-se o que é a mediação digital, enfrentando a acepção do conceito tradicional de mediação em virtude da introdução do que se denomina neste trabalho "quarto elemento".

Em seguida, parte-se para uma crítica do novo viés que toma a mediação na era digital. Sem deixar de reconhecer suas vantagens, levantam-se questionamentos e reflexões sobre os efeitos da mediação ocorrida em um ambiente digital. A falta de contato direto entre o mediador e

${ }^{1}$ No original: "People are not hooked on gadgets - they are hooked on each other".

Revista de Direito Brasileira | Florianópolis, SC | v. 28 | n. 11 | p.367-386 | Jan./Abr. 2021 
as partes compromete a mediação on-line? Como o facilitador poderá proporcionar um ambiente favorável sem o estabelecimento de uma conexão pessoal? Há violação do princípio da isonomia quando o mediador intervém para suprir uma dificuldade no acesso à tecnologia ou uma deficiência da parte que a leve a uma situação de desigualdade? A criação de um registro eletrônico compromete a confidencialidade? Como assegurar a confidencialidade quando não há confiança nos dados armazenados? Há confidencialidade na mediação on-line?

Delimitadas as reflexões suscitadas pela mediação em ambiente digital, enfrentar-se-á cada um dos questionamentos levantados mediante uma abordagem principiológica, adaptando-se os princípios da mediação tradicional ao ambiente digital, analisando-os agora à luz de novos paradigmas.

Ao final, conclui-se que a mudança de paradigma da mediação on-line importa em alteração não na sua acepção, mas na natureza da interação e nas habilidades necessárias para gerenciar a comunicação e a troca de informações entre as partes e os mediadores. Os novos arquétipos introduzidos na era digital pelo quarto elemento exigem, essencialmente, mudança nas relações e habilidades do mediador.

\section{A MEDIAÇÃO NO AMBIENTE DIGITAL}

\subsection{Modos de resolução de disputa on-line}

Na conferência da International Chamber of Commerce (ICC), ocorrida em junho de 2017, intitulada "Igualdade de acesso à informação e justiça: resolução de litígios em linha", cujo objetivo era a resolução de disputas on-line, chegou-se à conclusão de que as tecnologias digitais desempenharão um papel cada vez mais central na resolução de conflitos. Na ocasião, Mohamed Abdel Wahab, sócio fundador e chefe de arbitragem internacional da Zulficar \& Partners Law Firm (Cairo, Egito), afirmou: "Não falamos mais de tecnologia e resolução de disputas on-line como um luxo ou subproduto",

A era digital transformou a forma como se comunicam os indivíduos, desconstituindo as fronteiras físicas e provocando uma mudança de paradigma. Os modos de solução on-line de conflitos (ODR) não são apenas um processo mais eficiente do que os meios alternativos de resolução de conflitos (em inglês, alternative dispute resolution (ADR) $)^{3}$, mas representam também uma mudança de mentalidade. A ADR trouxe uma nova mentalidade, e assim fará a ODR (RABINOVICH-EINY; KATSH, 2014, p. 6).

Os meios alternativos de resolução de conflitos (ADR), como a mediação, a conciliação e a arbitragem, têm como característica comum incentivar a cooperação das partes na busca de um meio-termo que satisfaça a todos (DEVANESAN; ARESTY, 2012, p. 273). A origem dos ODRs está vinculada aos ADRs em um novo espaço instituído pela internet (AMORIM, 2017, p. 517). São métodos de resolução de controvérsias que se valem da tecnologia, permitindo uma melhor acessibilidade. Diz Arbix (2017, p. 214): “ODR é a resolução de controvérsias em que as tecnologias de informação e comunicação não se limitam a substituir canais de comunicação tradicionais, mas agem como vetores para oferecer às partes ambientes e procedimentos ausentes em mecanismos convencionais de dirimir conflitos".

Segundo Rainey (2014, p. 39), a definição clássica de ODR vem dos primórdios do $e$ commerce, quando a National Science Foundation (NSF) dos EUA suspendeu a proibição do comércio on-line em 1992. A partir daí, começaram a aparecer disputas diferentes das que eram habitualmente conhecidas, pois se tratava de conflitos criados on-line cujas partes se encontravam em locais geograficamente distantes. Assim, em meados da década de 90 do século XX, alguns

\footnotetext{
${ }^{2}$ No original: "We no longer speak of technology and online dispute resolution as a luxury or by-product".

${ }^{3}$ Também são denominados "meios alternativos de resolução de controvérsias" (MASC) ou "meios extrajudiciais de resolução de controvérsias" (MESC).
} 
profissionais de ADR perceberam que a comunicação on-line emergente estava tendo um impacto, principalmente na área comercial, e cunharam o termo "resolução de disputa on-line (ODR)" para descrever e diferenciar o que eles viam como um novo local para a resolução de disputas.

A ODR, portanto, não se refere ao uso da tecnologia em um sistema judicial já existente. A tecnologia como anexo ou facilitador da recepção, da pesquisa e do armazenamento de documentos é um avanço no sistema judicial, mas não é ODR. Também a comunicação on-line, como forma de permitir que as partes deem queixa, quando associada a um mecanismo de resolução de litígios, não deve ser considerada como ODR. Mecanismos que permitem aos clientes reclamar nada mais são do que instalações de atendimento ao cliente on-line, e não ODR. O verdadeiro sistema ODR é aquele que permite às partes mais do que simplesmente reclamarem - a plataforma deve envolver a resolução de uma disputa e usar um facilitador neutro (mediação) ou um tomador de decisão (arbitragem) (RAYMOND; SHACKELFORD, 2013, p. 500).

As plataformas ODR envolvem a resolução de uma disputa. E, embora originalmente o termo ODR se referisse à resolução de conflitos que surgiam em um ambiente on-line (nomeadamente na configuração de e-commerce ou fóruns sociais on-line), com o tempo, diante da oferta de ferramentas e de sistemas tecnológicos, o uso dos métodos de solução de conflitos online expandiu-se também para a resolução de disputas tradicionais off-line (RABINOVICH-EINY; KATSH, 2014).

Logo, a resolução de litígios on-line (ODR) pode ocorrer total ou parcialmente on-line e diz respeito a dois tipos de disputas: aquelas que surgem no ciberespaço e as que surgem off-line, podendo valer-se de mecanismos tradicionais de solução de conflitos, como a negociação, a mediação e a arbitragem (GOODMAN, 2003).

A ODR tem-se expandido cada vez mais, mudando a visão do meio on-line e da comunicação digital pelos recursos que oferece, permitindo flexibilidade e eficiência e propiciando novas oportunidades de procedimentos para uma solução eficaz (RABINOVICH-EINY; KATSH, 2014, p. 9); por isso, tem sido apontada como uma opção de acesso à justiça (RAYMOND; SHACKELFORD, 2013, p. 486).

Hoje a ODR é uma realidade, existindo várias experiências no direito comparado, como, por exemplo, o Civil Resolution Tribunal no Canadá, a plataforma comunitária na Europa, a qual, como ocorre com a plataforma brasileira consumidor.gov.br, resolve disputas nas relações de consumo. Também no Brasil podem-se apontar várias iniciativas de ODR, como Justto, Acordo Fechado, Concilie Online, Juster Resolução de Conflitos, Arbitranet, D’acordo mediações, bem como a plataforma de Mediação Digital do Conselho Nacional de Justiça (CNJ).

Enfim, os meios de solução de conflitos on-line (ODR) são métodos de resolução de controvérsias, surgidos em ambiente tanto on-line como off-line, que se valem da tecnologia de informação e comunicação e permitem a utilização dos mecanismos tradicionais de solução de conflitos, como a negociação, a mediação e a arbitragem em ambiente digital.

\subsection{O que é mediação on-line?}

A mediação é um dos "meios alternativos de resolução de conflitos", no qual um terceiro, imparcial, atua, de forma ativa ou passiva, como facilitador do processo de retomada do diálogo entre as partes, antes ou depois de instaurado o conflito (CAHALI, 2012, p. 57).

O prefácio do Model standards of conduct for mediators, adotado pela American Arbitration Association, pela American Bar Association's Section of Dispute Resolution e pela Association for Conflict Resolution (2005), enfatiza que a mediação serve a vários propósitos, incluindo a oportunidade para que as partes definam e esclareçam questões, compreendam diferentes perspectivas, identifiquem interesses, explorem e avaliem possíveis soluções, e alcancem mutuamente acordos, quando o desejarem. 
A mediação é, assim, um método autocompositivo no qual um terceiro imparcial facilita a comunicação e a negociação entre as partes (KOVACH; LOVE, 1988, p. 106), resolvendo suas disputas construtivamente e explorando estratégias que venham a prevenir ou a resolver futuras controvérsias (WANDERLEY, 2004, p. 19), pois seu fulcro é manter a continuidade das relações das pessoas envolvidas no conflito e promover a tomada de decisão voluntária das partes na controvérsia (HAYNES; MARODIN, 1996, p. 11).

Ao contrário do processo judicial, a mediação possui uma organização lógica, característica de um método de resolução de disputas. Trata-se, portanto, de uma proposta transformadora do conflito, porque busca a sua resolução pelas próprias partes, que recebem auxílio do mediador para administrá-lo (WARAT, 2001, p. 21).

A mediação digital, bem como todas as demais formas de resolução de disputas assistidas por tecnologia, não é apenas um análogo processo do que ocorre na mediação tradicional face a face. Existem mudanças na natureza, na interação e nas habilidades necessárias para gerenciar a comunicação e a informação de troca, que podem ter um impacto sobre as partes e o mediador (RAINEY, 2014, p. 55).

O conceito de mediação não será alterado no meio digital, contudo, como há, além das partes, um quarto sujeito (RABINOVICH-EINY, 2006) ou uma quarta parte (RAINEY, 2014) que aqui denominamos "quarto elemento", por não se tratar de pessoa física -, que é a tecnologia, será necessário adaptar as concepções e os princípios da mediação a um ambiente digital, a fim de que o mediador possa conduzir o processo com mais esse novo elemento.

Nesse passo, a primeira questão a ser esclarecida é o que deve ser considerado mediação on-line: se apenas a mediação que é conduzida exclusivamente no meio digital, ou também aquela que não é realizada totalmente em um canal de comunicação on-line, mas na qual a tecnologia pode ser utilizada como meio paralelo de informação e comunicação.

Segundo entendimento adotado pela United Nations Commission on International Trade Law (UNCITRAL) (2013) ${ }^{4}$, uma plataforma ODR é um sistema para gerar envio, recebimento, armazenamento, troca ou processamento de comunicações usadas na resolução de disputas on-line, entendendo-se, assim, que qualquer procedimento de solução de controvérsia em que um Webbased é utilizado pode ser chamado ODR (PHILIPPE, 2014, p. 59).

Como visto, o sistema ODR é aquele que permite às partes resolverem seus conflitos pelo uso da tecnologia (RAYMOND; SHACKELFORD, 2013, p. 500); logo, independentemente do mecanismo realizado e desde que a tecnologia da informação seja utilizada, o serviço oferecido para a solução de controvérsias é considerado ODR.

O que importa, portanto, é que a tecnologia seja usada não apenas para armazenamento de dados, mas também para a solução de uma controvérsia. Assim, se na mediação foi utilizada tecnologia de informação, ainda que o procedimento não tenha sido conduzido exclusivamente online, pode-se considerar uma mediação digital, sendo seus procedimentos chamados ODR.

A mediação digital é, portanto, um método autocompositivo em que as partes são as protagonistas da solução, auxiliadas por um terceiro mediador, independente e imparcial, que, em um ambiente digital, utiliza técnicas para que os interessados sejam estimulados a solucionar o conflito. Ocorre por meio de plataforma, onde o mediador, com técnicas adequadas, cria um ambiente acolhedor e favorável para que os envolvidos possam conversar, auxiliando-os a encontrar em conjunto propostas construtivas e criativas que busquem atender seus interesses.

Vê-se que a acepção da mediação não se altera no meio digital. Contudo, havendo um quarto elemento - a tecnologia - modificando a forma como as pessoas se comunicam, há, necessariamente, uma mudança na sua atividade, que vai exigir uma nova interação entre os sujeitos envolvidos - partes e mediadores.

\footnotetext{
${ }^{4}$ A UNCITRAL é o órgão legal central do sistema das Nações Unidas no campo do direito comercial internacional, com participação universal especializada em reforma da legislação comercial em todo o mundo há mais de 50 anos.

Revista de Direito Brasileira | Florianópolis, SC | v. 28 | n. 11 | p.367-386 | Jan./Abr. 2021
} 


\section{NOVOS CONTORNOS DA MEDIAÇÃO COM O ADVENTO DO QUARTO ELEMENTO}

Como a mediação off-line, a mediação on-line permite que o mediador adapte o processo para atender às necessidades particulares dos disputantes (GOODMAN, 2003). Lide (1996, p. 219) já havia identificado que a mediação, juntamente com a arbitragem e outros métodos ADR, é mais propícia no meio eletrônico, em razão da maior flexibilidade que admite, permitindo soluções criativas e decisões mais rápidas.

Reconhecidamente, o grande benefício da mediação on-line é o encurtamento das distâncias (HANG, 2001), o que implica redução de tempo e de custos (DEVANESAN; ARESTY, 2012, p. 265), principalmente quando as disputas surgem entre indivíduos de países diferentes, pois permite que as partes participem da mediação de seus respectivos negócios ou residências (MELAMED; HELIE, 1999).

Diminuindo distâncias, a tecnologia de comunicação facilita e incentiva a mediação online (RAYMOND; SHACKELFORD, 2013, p. 500). Não havendo necessidade de agendamentos, de locais para reuniões, as partes podem participar da mediação em momentos convenientes, e o mediador pode reunir-se com uma ou ambas as partes em particular, sem afetar o fluxo da mediação (GOODMAN, 2003).

Por tais razões, Vannieuwenhuyse (HOGAN LOVELLS PUBLICATIONS, 2018) admitiu o uso de videoconferência na arbitragem, não apenas para diminuir os custos, mas como forma de expandir o seu mercado.

Aponta-se, ainda, como vantagem da mediação on-line, a edição de mensagens antes de enviá-las (MELAMED, 2002), evitando-se as respostas impulsivas que ocorrem na mediação face a face, o que é particularmente vantajoso quando o litígio envolve questões de família e os sentimentos estão muito exaltados (DEVANESAN; ARESTY, 2012, p. 284).

Pelas facilidades apontadas acima - baixo custo, encurtamento de distâncias -, não é sem razão que a mediação no ciberespaço é apontada como um veículo que permite a melhoria do acesso dos indivíduos à justiça (RAYMOND; SHACKELFORD, 2013, p. 500).

Uma desvantagem dos sistemas judiciais convencionais é a pouca flexibilidade nos procedimentos usados para lidar com casos que surgem em diferentes contextos. Ao lidar com litígios transfronteiriços, que surgem em situações on-line entre cidadãos de diferentes países, o uso de tribunais convencionais provoca grandes dificuldades, pois pelo menos uma parte deve viajar para a jurisdição da outra para julgar a reivindicação (DEVANESAN; ARESTY, 2012, p. 284). Sem dúvida, a mediação on-line surge com alternativa de flexibilidade e acesso para a resolução de disputas.

Contudo, não obstante suas vantagens, a mediação digital não é uma unanimidade, porque havendo, além das partes e do mediador, um quarto elemento (a tecnologia de comunicação e informação), que provoca alterações na forma de comunicação, há necessidade de adaptações na sua atividade como tradicionalmente concebida.

A primeira questão que se pode apontar é a falta de um contato direto entre o mediador e as partes na mediação on-line, pois, como a mediação digital não substitui a conversa face a face, essa prática de mediação tradicional não pode ser reproduzida em um ambiente digital (FRIEDMAN, 2013).

Se a mediação é uma forma oral de resolução de disputas destinada a envolver os participantes em relações interpessoais diretas (CAHALI, 2012, p. 57), sendo baseada em sessões face a face (KOVACH; LOVE, 1988, p. 106), para ajudar as partes a chegarem a uma resolução de sua disputa (WARAT, 2001, p. 21), como pode ser realizada em um ambiente onde não há uma conexão pessoal?

A mediação tradicional procura levar as partes a uma solução negociada, considerando fatores psicológicos (CAMPBELL, 2016), representando para alguns participantes a oportunidade 
de contar a versão do caso diretamente à outra parte, expressando suas emoções e sentimentos (EISEN, 1998, p. 1323).

A mediação on-line, contudo, perde essa dinâmica por ocorrer a distância e na frente da tela do computador (EISEN, 1998, p. 1325), havendo barreiras para o diálogo porque normalmente não há conexão ou qualquer contato pessoal entre as partes, nem qualquer esperança de um futuro relacionamento, pois, na maioria das vezes, as disputas cibernéticas envolvem uma "transação única" (GOODMAN, 2003).

A falta de uma conexão pessoal na mediação digital impede que os participantes transmitam suas personalidades ou seus sinais físicos, sendo difícil o mediador usar as pistas intuitivas do corpo, da linguagem, da expressão facial e da tonalidade verbal que fazem parte da mediação tradicional e possibilitam ao facilitador avaliar a flexibilidade de uma determinada parte (GOODMAN, 2003).

A barreira da falta de contato direto entre as partes e o mediador em razão da tecnologia exigirá novas habilidades do mediador. Como o facilitador poderá proporcionar um ambiente favorável sem o estabelecimento de uma conexão pessoal?

Outra questão a ser salientada decorre da própria inacessibilidade das partes à mediação on-line, pela falta de conhecimento da tecnologia ou das plataformas do sistema de mediação digital. Como lembra Goodman (2003), embora a mediação cibernética seja uma das alternativas menos dispendiosas para resolver disputas, ainda existe um custo que envolve o acesso à tecnologia, que pode ser difícil para muitas pessoas, o que faz com que a negociação cibernética esteja fora do alcance de muitas disputas na internet.

As dificuldades no acesso à tecnologia ou as deficiências das partes podem levá-las a uma situação de desigualdade. Nesse caso, o mediador deverá intervir? Haverá violação do princípio da isonomia? O desconhecimento tecnológico pode ser suprido com uma intervenção do mediador sem comprometer a isonomia das partes?

Apesar das questões acima, de todas as características da mediação que precisam ser revisitadas na era digital, a confidencialidade é a que mais tem sido objeto de preocupação (GOODMAN, 2003; KATSH, 1996; RABINOVICH-EINY, 2006; RAINEY, 2014). Enquanto a mediação tradicional não cria um registro físico, a mediação on-line cria um registro eletrônico, não havendo segurança no material confidencial na ODR, o que compromete a confidencialidade, dificultando o intercâmbio aberto e honesto no canal de comunicação digital na medida em que as partes não se sentem seguras para se utilizarem da via digital.

Sendo a confidencialidade um dos pilares mais importantes da mediação, a falta de confiança no armazenamento dos dados poderá, a princípio, inibir as partes, limitando a ação do mediador e, assim, comprometendo o sucesso da mediação. É o nó górdio da mediação on-line. Há confidencialidade na mediação digital?

Observa-se que, efetivamente, houve uma mudança de paradigma na mediação. As situações acima apontadas ratificam uma mudança na forma como ela deve ser conduzida e na interação entre as partes e o mediador em virtude da introdução do "quarto elemento", provocando reflexões e questionamentos sobre o novo viés que toma a mediação na era digital.

A mediação, como método de solução de conflitos, precisa de novos paradigmas para ser eficaz no ambiente on-line. Embora a comunicação seja o elemento de todo processo de solução de disputas, o mediador precisa adaptar-se às novas formas de comunicação e administrar o fluxo dessas novas informações trazidas.

No capítulo seguinte, analisar-se-ão as questões acima à luz dos novos paradigmas dos princípios da mediação on-line, que, em razão da introdução de um quarto elemento, exige uma adaptação dos já conhecidos princípios da mediação tradicional ao novo ambiente digital. 


\section{OS PRINCÍPIOS DA MEDIAÇÃO ON-LINE: UMA ANÁLISE À LUZ DO QUARTO ELEMENTO}

\subsection{Confidencialidade}

A confidencialidade é apontada como um princípio fundamental da mediação (ALMEIDA, 2015, p. 85), que visa resguardar o diálogo realizado ao longo das sessões da mediação, impedindo que as informações prestadas a título confidencial ao mediador por uma das partes sejam comunicadas, sem o seu consentimento, às restantes partes envolvidas no procedimento ou a terceiros.

O sigilo das informações é a característica central da mediação e em grande medida o que atrai os litigantes, porque permite às partes revelarem suas verdadeiras preocupações e necessidades, sem medo de que tais informações sejam divulgadas caso a disputa acabe em litígio, razão por que a confidencialidade é prestigiada em vários ordenamentos jurídicos.

A JAMS Mediation, Arbitration and ADR Services, ([20--?], diretriz IV), uma organização com fins lucrativos sediada nos Estados Unidos, prevê entre as Diretrizes de Ética dos Mediadores, que o mediador e todas as partes tenham um claro entendimento quanto à confidencialidade. Enfatiza que o mediador não pode divulgar informações confidenciais sem a permissão de todas as partes ou a menos que exigido por lei, regra judicial ou outra autoridade legal, nem usar informações confidenciais adquiridas durante a mediação para obter vantagens ou vantagens pessoais para os outros, ou para afetar adversamente os interesses dos outros.

A Lei de Mediação portuguesa (Lei n. ${ }^{\circ}$ 29/2013) também prevê que o procedimento de mediação tem natureza confidencial, devendo o mediador de conflitos manter sob sigilo todas as informações de que tenha conhecimento no âmbito do procedimento de mediação, delas não podendo fazer uso em proveito próprio ou de outrem (Lei n. ${ }^{\circ}$ 29/2013, art. 5., 3$) .^{2}$ ).

Em nosso país, o princípio da confidencialidade está previsto no artigo 166 do Código de Processo Civil, no artigo 1. ${ }^{\circ}$, I, do Anexo III da Resolução n. ${ }^{\circ}$ 125/2010 do CNJ e no artigo 30 da Lei de Mediação (Lei n. ${ }^{\circ}$ 13.140/2015). Aplica-se a todos os envolvidos no procedimento da mediação, incluindo terceiros (mediador, partes e seus prepostos, advogados, assessores técnicos e todas as pessoas que tenham, direta ou indiretamente, participado do procedimento de mediação) e alcança toda e qualquer informação no âmbito da mediação: a) declaração, opinião, sugestão, promessa ou proposta formulada por uma parte à outra na busca de entendimento para o conflito; b) reconhecimento de fato por qualquer das partes no curso do procedimento de mediação; c) manifestação de aceitação de proposta de acordo apresentada pelo mediador; d) documento preparado unicamente para os fins do procedimento de mediação (Lei n. ${ }^{\circ}$ 13.140/2015, art. 30).

O sigilo recai sobre todas as informações das quais o mediador tenha conhecimento no procedimento de mediação, delas não podendo fazer uso em proveito próprio ou de outrem, e incide tanto sobre os envolvidos quanto sobre terceiros, devendo todos manter resguardadas as comunicações (ALMEIDA; PANTOJA; ANDRADE, 2016, p. 62).

Reiteradamente a doutrina reconhece que a confidencialidade cria um refúgio seguro para os litigantes, permitindo-lhes gerar disputas que eles não estavam dispostos a buscar por meio de vias públicas; uma vez iniciada a mediação, a confidencialidade incentiva as partes a participar de forma sincera, fazendo-as abandonar a conduta estratégica que utilizam normalmente por medo de futuros litígios (RABINOVICH-EINY, 2006, p. 265). Admite-se que a confiança na confidencialidade permite a livre expressão de ideias e opções que, por muitas razões, podem não surgir em um processo em que as informações se tornam parte do registro público ou podem ser usadas como evidência (RAINEY, 2014, p. 39).

As proteções de confidencialidade resultam da preocupação de que a divulgação de comunicações de mediação em procedimentos subsequentes não apenas diminuiria a franqueza das 
partes, mas também reduziria a confiança do público em geral no processo e impediria que futuros disputantes o usassem (RABINOVICH-EINY, 2006, p. 265).

Não é surpreendente que a preocupação com a confidencialidade seja um componente essencial da prática de mediação.

No entanto, a introdução da ODR tem desafiado as expectativas comuns em relação à confidencialidade. Enquanto as partes podem comprometer-se em manter tais informações em segredo no ambiente face a face, controlar as informações das partes sobre tais informações pode ser difícil em algumas ODR, porque muitas vezes as informações são conectadas a outras organizações ODR, tornando os dados das partes cada vez mais integrados a outros dados recolhidos por essas organizações. Embora haja uma maior eficiência do controle do processo, há o risco de que o acesso a informações sobre disputas possa afetar a integridade e o sucesso de processos alternativos (RABINOVICH-EINY; KATSH, 2014, p. 28).

A grande questão que envolve a confidencialidade no ambiente on-line é a dificuldade de preservação das informações e o risco de que tais informações sejam acessadas e comprometam o sucesso da mediação. Então, como manter a confidencialidade em uma mediação on-line? Como garantir a segurança das informações? O simples fato de colocar a informação em um ambiente público viola o princípio da confidencialidade?

A tecnologia de comunicação é mais um "elemento" no processo da mediação on-line e sua atuação não pode ser desprezada, pois o mediador não tem como dar segurança às partes se as informações são trocadas em uma comunicação on-line, o que acaba mudando o prisma da análise da confidencialidade no ambiente digital.

Diz-se que não é possível garantir a segurança das informações passadas com tecnologia diante do risco de serem violadas, tenha sido a mediação on-line feita numa sessão pública, com todas as partes presentes, ou numa sessão de mediação particular (RAINEY, 2014, p. 39).

Tal qual na mediação off-line, na mediação on-line, o facilitador deve cientificar as partes para que tenham um claro entendimento quanto à confidencialidade, explicando, antes do início da sessão de mediação, todas as regras que proíbem a divulgação das declarações feitas e dos documentos produzidos durante a sessão.

Essas questões não serão alteradas no mundo digital, pois a tecnologia não modifica nenhuma das condições da confidencialidade no mundo tecnológico (RAINEY, 2014, p. 39), contudo, em razão da existência do quarto elemento - a tecnologia -, sobre o qual o mediador não tem nenhum controle, os riscos deverão ser comunicados às partes, que deverão estar cientes da possibilidade de divulgação das informações. Ainda que as informações não venham a ser propagadas, deve o facilitador on-line mostrar às partes as gravidades que assumem, podendo recomendar o uso de tecnologias mais seguras com base em seus conhecimentos, cabendo às partes a opção (RAINEY, 2014, p. 39). A confiança pode ser alcançada sempre que se dá garantias às partes, em qualquer relacionamento ou transação, de que elas terão a opção de resolver os problemas que eventualmente possam surgir (RABINOVICH-EINY; KATSH, 2014, p. 30).

Não é demais lembrar que, mesmo na mediação off-line, há sempre riscos com documentos em papel, e as partes sempre têm de fazer escolhas sobre os locais e canais que estão dispostas a usar (RAINEY, 2014, p. 39).

Logo, o mediador deve descrever o direito de confidencialidade e a segurança real das informações trocadas em um ambiente digital, de forma que as partes possam fazer uma escolha informada sobre os riscos do consentimento da mediação on-line.

Mas ainda há outra questão a ponderar.

Os mesmos fins podem ser alcançados por meio de uma variedade de meios, e novos instrumentos podem surgir à medida que novas tecnologias vão aparecendo. Assim, embora a eliminação de um lugar físico e a insegurança do meio tecnológico possam ter um impacto na confidencialidade, sendo apontados como uma desvantagem que restringe a aplicabilidade e o alcance da mediação on-line, a longo prazo ficarão cada mais menos significativos conforme as 
capacidades tecnológicas vão se tornando mais ricas (RABINOVICH-EINY; KATSH, 2014, p. 3034).

Não obstante a insegurança do meio, tem-se admitido que, à medida que a tecnologia de informação vai se incorporando à vida das pessoas, mais ela promove a interação social - ainda que de uma forma diferente, derrubando suas resistências (RAINIE; WELLMAN, 2012, p. 39) -, o que acaba, paulatinamente, eliminando a insegurança do meio tecnológico.

Por outro lado, a insegurança na tecnologia passa a ser menos significativa quando a eficiência da justiça é atingida (RAYMOND; SHACKELFORD, 2013, p. 486).

É de se considerar que as partes esperam que os processos de resolução de litígios preencham os critérios de justiça processual - permitir voz, tratá-las com respeito, ser neutra - e ajustam suas expectativas para o meio no qual se dá a resolução dos conflitos, ainda que seja o meio digital. Mesmo que as partes saibam que a mediação é realizada por um software, o que importa é se é capaz de preencher os critérios da justiça processual. (RABINOVICH-EINY; KATSH, 2014, p. 30).

Desse modo, a confiança na tecnologia é uma barreira que deve ser suavizada com o tempo porque primam outros valores que as partes também almejam e suas expectativas podem ser atingidas independentemente do meio de resolução de conflitos.

Enfim, na análise da confidencialidade no ambiente on-line, deve-se considerar, além das partes e do mediador, a tecnologia como um quarto elemento do processo de mediação. Os mediadores devem considerar cuidadosamente como descrever os riscos e benefícios para as partes de uma maneira que permita uma decisão verdadeiramente informada pelos interessados.

\subsection{Autonomia da vontade das partes}

A autonomia da vontade das partes ou a não obrigatoriedade da mediação baseia-se na garantia de respeito à individualidade de cada sujeito e não se restringe à aceitação ou não da mediação, concerne também à escolha do mediador, do procedimento, do número de sessões etc. (PEIXOTO, 2018, p. 97).

As partes têm o direito de decidir se querem a mediação, cada qual fazendo escolhas livres quanto ao processo ou ao resultado, podendo exercer sua autonomia em qualquer fase da mediação, como selecionar o mediador, construir o processo, participar e retirar-se do procedimento de mediação quando quiserem.

Segundo as Diretrizes de Ética dos Mediadores do modelo JAMS Mediation, Arbitration and ADR Services ([20--?]), o mediador deve conduzir a mediação com base no princípio da autodeterminação, permitindo que a parte faça escolhas livres e informadas quanto ao processo e resultado, podendo, a qualquer momento, escolher o mediador, sair do processo etc.

A Lei da Mediação de Portugal, sob o título princípio da voluntariedade, estatui que o procedimento de mediação é voluntário, sendo necessário obter o consentimento esclarecido e informado das partes para a realização da mediação. Em qualquer momento, as partes podem, conjunta ou unilateralmente, revogar o seu consentimento para a participação no referido procedimento (Lei n. ${ }^{\circ}$ 29/2013, art. $4 .^{\circ}$ ).

De acordo com o princípio da autonomia da vontade das partes, as sessões de mediação não devem ocorrer se os envolvidos não quiserem participar delas. A autonomia está ligada diretamente à vontade dos próprios envolvidos de terem ou não a situação gerida pela mediação.

Embora, pelo princípio da autonomia, informe que as partes fazem a opção pelo processo de mediação, o nosso próprio CPC, no seu artigo 334, prevê a mediação como etapa obrigatória dentro do procedimento jurisdicional, inclusive admitindo que, se a parte intimada da audiência de mediação não comparecer, será punida sob a justificativa de ato atentatório à dignidade da justiça no valor de $2 \%$ do valor da causa ou da vantagem econômica pretendida. 
Apesar de tal princípio não ter sido recepcionado na mediação jurisdicional, é indispensável à condução da mediação, permitindo que os envolvidos sintam-se mais à vontade porque têm autonomia para impulsionar e encaminhar a mediação conforme se sentirem confortáveis, atendendo assim ao fulcro da mediação. Conforme diz Rainey (2014, p. 46), “o mandato de autodeterminação está no centro da prática de mediação"s.

O princípio da autonomia da vontade está previsto no artigo $2^{\circ}$, V, da Lei de Mediação brasileira (Lei n. ${ }^{\circ}$ 13.140/2015) e no artigo $1^{\circ}$, II, do Anexo III da Resolução n. ${ }^{\circ}$ 125/2010 do CNJ que estatui, como regra de conduta do mediador, o dever de respeitar os diferentes pontos de vista dos envolvidos, assegurando-lhes que cheguem a uma decisão voluntária e não coercitiva, com liberdade para tomar as próprias decisões no curso ou ao final do processo e para interrompê-lo a qualquer momento.

Do mesmo modo, na mediação on-line, as partes podem exercer a autonomia em qualquer estágio de uma mediação, incluindo na seleção de mediadores, na seleção de plataformas, na concepção de processos etc. Contudo, existem algumas situações novas que surgem no campo digital a serem consideradas, em virtude de um elemento novo, que é a tecnologia.

Enquanto na mediação off-line, o mediador pode desenvolver várias estratégias para atender aos interesses das partes, conforme suas necessidades, na mediação on-line pode haver uma limitação na ferramenta disponibilizada pelo servidor, o que restringe as possibilidades de condução e de adequação do procedimento às especificidades do caso.

Rainey (2014, p. 46) aponta situações em que o mediador se defronta no seu mister com dificuldades ligadas ao uso da tecnologia: seja porque as partes solicitam o uso de uma ferramenta que ele não domina, seja porque ele tenta influenciar as partes para que adotem a plataforma que ele sabe manejar. Nesses casos, sendo o uso da plataforma limitativa quanto à adequação ao interesse das partes, haveria violação do princípio da autonomia?

Em verdade, tais situações somente ocorrem em um ambiente diferente, que é o meio digital, mas são situações já conhecidas e vivenciadas no ambiente da mediação face a face. Assim, tal qual no procedimento adotado na mediação off-line, quando o mediador deve dialogar para ajustar seu procedimento ao interesse das partes ou vice-versa, o ambiente on-line apenas exige outro tipo de diálogo.

O mediador deve dar atenção às preferências das partes e aos níveis de conforto em relação ao uso da tecnologia, deve ter certeza de que ambas as partes estão igualmente dispostas a utilizar quaisquer ferramentas online disponíveis e que têm razoavelmente igual facilidade para utilizá-las (RAINEY, 2014, p. 47).

Toda flexibilização no processo de mediação on-line deve ser marcada por um intenso diálogo, devendo o mediador discutir as opções com as partes, questionando interesses, desenvolvendo opções e alternativas na tentativa de elaborar uma resolução.

Desse modo, o que muda da mediação off-line para a mediação on-line é apenas o ambiente tecnológico, devendo o mediador conversar com as partes sobre a seleção de plataformas, a concepção de procedimentos etc., ajudando-as a chegar a uma decisão voluntária, com liberdade para tomar as próprias decisões durante todo o processo de mediação.

\subsection{Isonomia das partes}

Pelo princípio da isonomia das partes, os participantes da mediação devem manifestar-se igualmente e estar em igualdade de condições na realidade prática para que isso se reflita nas sessões de mediação (TARTUCE, 2015, p. 212).

${ }^{5}$ No original: "The mandate for self-determination is at the centre of the practice of mediation". 
A JAMS Mediation, Arbitration and ADR Services ([20--?], diretrizes V e VI) enfatiza que o facilitador é o intermediário neutro e não o representante ou defensor de qualquer parte, não podendo oferecer aconselhamento jurídico a uma parte.

Na Lei de Mediação de Portugal, o princípio da isonomia, cunhado sob o princípio da igualdade, afirma que as partes devem ser tratadas de forma equitativa durante todo o procedimento de mediação, cabendo ao mediador de conflitos gerir o procedimento de forma a garantir o equilíbrio de poderes e a participação de ambas as partes (Lei n. ${ }^{\circ} 29 / 2013$, art. 6. ${ }^{\circ}$ ).

Previsto no artigo 2..$^{\circ}$, II, da Lei de Mediação brasileira (Lei n. $\left.{ }^{\circ} 13.140 / 2015\right)$, o princípio da isonomia preza a condução do comportamento igualitário entre as partes.

Contudo, os interessados podem apresentar desigualdades, em relação às questões financeiras, sociais ou mesmo dentro do relacionamento, podendo haver a sobreposição de forças de uma sobre a outra, o que exige do mediador a condução da mediação ante a desigualdade das partes.

Entende-se que o mediador, por ter uma postura transformativa, não deve agir ativamente na tentativa de igualar poderes daqueles que percebe serem mais frágeis: por um lado, isso acarretaria uma falha de sua isenção enquanto terceiro neutro ante os envolvidos; por outro, o mediador, assumindo uma postura transformativa, ao privilegiar aqueles que acredita se encontrarem em situação de desvantagem, deixaria de encorajar o "autofortalecimento" do envolvido, que permitiria a essa parte desenvolver-se e enfrentar futuras situações com autonomia (TARTUCE, 2015, p. 59). A postura do mediador em situações com essa é informar os interessados acerca da assistência de um advogado para que fiquem mais bem amparados e mais confortáveis no procedimento (ALMEIDA; PANTOJA; ANDRADE, 2016, p. 59).

O mediador deve garantir o tratamento igualitário das partes durante todo o procedimento de mediação, gerindo o desequilíbrio entre elas sem, no entanto, privilegiar aquela que acredita ser a mais frágil.

A isonomia é relevante para o caminhar da mediação num ambiente tanto on-line como off-line, na medida em que, por meio dela, as partes também se encontram seguras e confortáveis em um diálogo que pode priorizar todos os envolvidos. Contudo, na mediação digital, o uso da tecnologia pode provocar desigualdades, havendo outras questões a serem enfrentadas pelo mediador, que, além de concentrar-se no problema em si, deverá analisar os entraves que pode gerar o quarto elemento na mediação, pelo desconhecimento do manuseio pelas partes.

Com efeito, algumas pessoas não são capazes de usar o computador sem alguma ajuda. Caberá ao mediador analisar se as partes têm condições de usar a ferramenta tecnológica para realizar a mediação, bem como sopesar se essa barreira tecnológica está tornando-se um entrave e dificultando a mediação (RAINEY, 2014, p. 48).

A solução sempre será o diálogo. Assim, em uma conversa privada com cada parte antes da mediação inicial, o facilitador poderá ter condições de analisar o nível de conforto de cada uma, seus conhecimentos em informática, bem como seu interesse em usar a mediação on-line.

Deverá o mediador escolher a tecnologia com sabedoria, descrevendo-a para as partes de forma realista e preparando-as para usar o meio digital. Deverá, ainda, monitorar seu uso para identificar os sinais de dificuldade ou de desvantagem que alguma parte pode apresentar em razão da utilização de uma plataforma específica. Embora a maioria das ferramentas on-line disponíveis seja muito simples e possa ser usada pelas partes sem muito esforço, exigindo muito pouco em termos de formação, ainda é necessário que o mediador crie um ambiente em que os interessados sintam-se tratados de forma justa e assegure-se de que não achem que o próprio processo on-line esteja influenciando negativamente um possível resultado (RAINEY, 2014, p. 48).

Na mediação digital, o mediador deverá sempre monitorar as partes, pois, apesar de terem assentido na mediação, podem estar em desvantagem pelo uso da tecnologia. Nesse caso, identificando a desvantagem pelo uso da tecnologia, o mediador pode interromper o processo e ver 
se pode continuar de forma que seja aceitável para ambas as partes e que garanta a equidade processual (RAINEY, 2014, p. 52),

Enfim, o importante é que o mediador crie um ambiente em que as partes se sintam tratadas de forma justa e tenham certeza de que o processo on-line não as está prejudicando no resultado, e, percebendo que a tecnologia está colocando as partes em situação de disparidade, deverá determinar o fim da mediação.

\subsection{Oralidade}

O princípio da oralidade imprime maior celeridade ao procedimento, promove maior informalidade e fomenta a confidencialidade (MIRANDA NETTO; SOARES, 2016, p. 113), porque, realizando-se a mediação preferencialmente pela fala, permite maior participação do sujeito, dando-lhe empoderamento na resolução do conflito, uma vez que não precisa estar representado por alguém.

Na mediação off-line, a oralidade ocorre face a face (KOVACH; LOVE, 1988, p. 106), havendo o contato direto entre as partes, que podem expressar seus sentimentos em um ambiente de confiança, o que as leva à resolução de sua disputa (WARAT, 2001, p. 21).

Como a mediação digital ocorre a distância e na frente da tela do computador (EISEN, 1998, p. 1325), uma de suas grandes desvantagens apontadas seria a falta de um contato direto entre as partes, que impediria a criação de um ambiente de confiança propício para ajudá-las a chegar à resolução de sua disputa.

Não obstante as opiniões acima apontadas, a impessoalidade na mediação on-line é apontada, em algumas situações, como algo vantajoso, porque permite a resolução da disputa com a preservação do anonimato, que é altamente valorizado na internet (HANG (2001, p. 858).

Por outro lado, a falta de um contato direto entre as partes pode ser remediada com as inovações tecnológicas. A videoconferência, por exemplo, é apontada como a solução para a falta de encontros face a face nas resoluções de conflito on-line (HOGAN LOVELLS PUBLICATIONS, 2018; KATSH; RIFKIN; GAITENBY, 2000).

As pessoas cada vez mais têm utilizado a internet para se relacionarem. Programas de relacionamento têm aproximado pessoas de diferentes partes do mundo. Isso só comprova que as aparentes desvantagens da mediação digital provocadas pela falta de uma conexão pessoal (GOODMAN, 2003, p. 13) têm sido superadas pela própria internet, à medida que as pessoas tomam contato com a tecnologia.

Além disso, à medida que a tecnologia avança, com câmeras de vídeo integradas a computadores ou telefones, softwares de videoconferência de fácil acesso, modems rápidos para acomodar a videoconferência, as dificuldades pela falta de um contato direto entre as partes deverão ser superadas, sendo possível que no futuro, com a videoconferência on-line tornando-se cada vez mais disponível, seja até mais fácil para os disputantes empreenderem negociações online (GOODMAN, 2003, p. 15).

Para Vannieuwenhuyse (HOGAN LOVELLS PUBLICATIONS, 2018), a videoconferência não representa apenas uma forma de diminuir os custos na arbitragem, mas se trata de uma natural alteração na forma de comunicação, provocada pelo ambiente tecnológico, que vai pouco a pouco substituir os encontros face a face.

Desse modo, a falta de contato pessoal não é um obstáculo intransponível para a mediação on-line, exigindo apenas uma nova forma de adaptação para a interação entre partes e mediador no meio tecnológico. Assim como temos necessidade de nos adaptar às barreiras da linguagem, à deficiência auditiva, ao comprometimento da visão etc., devemos buscar novas maneira de lidar com as mudanças introduzidas pela tecnologia de comunicação. 


\subsection{Informalidade}

Segundo o princípio da informalidade, o procedimento da mediação deve ser conduzido de forma flexível, sem regras fixas ou preestabelecidas, pois a inexistência de formalismos permite que as partes sejam atendidas nas peculiaridades de cada caso concreto (MIRANDA NETTO; SOARES, 2016, p. 114).

Há na mediação uma flexibilidade que oferece uma maior confortabilidade às partes, facilitando suas participações no processo e fazendo com que cada mediação seja um procedimento único. Contudo, isso não significa ausência de regras ou ausência de parâmetros para a realização da mediação; ao contrário, permite que os indivíduos tenham uma compreensão de gestão de conflito mais adaptável e mais próxima da população e, consequentemente, permite que a situação conflituosa seja tratada mais adequadamente (MIRANDA NETTO; SOARES, 2016, p. 114).

Previsto no artigo 2. ${ }^{\circ}$, IV, da Lei de Mediação (Lei n. ${ }^{\circ}$ 13.140/2015), o princípio da informalidade diz respeito ao modo como o procedimento da mediação é desenvolvido, à simplicidade que deve marcar a mediação e, consequentemente, à responsabilidade com que o mediador tem de encaminhar a mediação, conforme os sujeitos envolvidos e suas necessidades.

O princípio da informalidade da mediação on-line suscita algumas questões ante a impossibilidade de flexibilização procedimental em virtude da limitação da plataforma ou site a ser utilizado.

As partes podem optar pelo uso de uma ferramenta de comunicação que ofereça uma maior flexibilidade, que seja, no entanto, comprovadamente menos segura ou sobre a qual o mediador não tenha domínio. Pode ocorrer, também, que as partes sacrifiquem a flexibilidade procedimental diante do custo ou da conveniência, ou optem por um procedimento misto, que associe o trabalho presencial ao uso de alguma tecnologia.

Como nos princípios anteriores, o diálogo, como característica da mediação on-line, deve marcar o seu procedimento, cabendo às partes a escolha de todo o caminhar da mediação, com o uso da tecnologia e de suas ferramentas na totalidade ou em parte do processo.

\subsection{Imparcialidade}

De acordo com o princípio da imparcialidade, o mediador tem de atuar sem favoritismos, isto é, sem pender para um dos lados ou para um dos interesses que estão em jogo na mediação, sem privilegiar uma das partes.

A JAMS Mediation, Arbitration and ADR Services ([20--?], diretriz V) prevê, nas

Diretrizes de Ética dos Mediadores, que o mediador deve permanecer imparcial durante todo o curso da mediação, devendo evitar preconceito com base nas origens, nos atributos pessoais ou na conduta das partes durante a sessão.

De acordo com a Lei de Mediação de Portugal, o mediador deve agir com as partes de forma imparcial durante toda a mediação (Lei n..$^{\circ}$ 29/2013, art. 6. ${ }^{\circ}$ ).

No Brasil, a imparcialidade vem prevista no artigo 166 do Código de Processo Civil e nos artigos 2. ${ }^{\circ}$, I, e 5. ${ }^{\circ}$ da Lei de Mediação (Lei n. $\left.{ }^{\circ} 13.140 / 2015\right)$; no artigo $1^{\circ}$, IV, do Anexo III da Resolução n. ${ }^{\circ}$ 125/2010 do CNJ, vem estatuído que o mediador deve agir com ausência de favoritismo, preferência ou preconceito, assegurando que valores e conceitos pessoais não interfiram no resultado do trabalho, compreendendo a realidade dos envolvidos no conflito e jamais aceitando qualquer espécie de favor ou presente.

Aplicam-se ao mediador as regras de impedimento e de suspeição previstas no artigo 148, II, do Código de Processo Civil de 2015.

A imparcialidade do mediador e, portanto, sua tarefa e sua responsabilidade de conduzir indistintamente o procedimento, oferecendo o mesmo espaço às partes, sem julgamentos e interesses do objeto do procedimento, proporcionam um ambiente mais confortável, promovendo 
o maior desenvolvimento dos mediados, que tendem a sentir-se mais seguros por tais ressalvas. Assim, além de um princípio ético, a imparcialidade também assegura melhores condições à mediação, angariando maior participação das partes (ALMEIDA; PANTOJA; ANDRADE, 2016, p. 128).

O princípio da imparcialidade liga-se a outro, que é o da independência, segundo o qual o mediador deve atuar sem pressões externas, sem coações por conta da mídia ou dos comportamentos sociais, não podendo desviar-se do que acredita ser mais adequado realizar na mediação no momento (SANTANNA; VERAS; MARQUES, 2016, p. 128).

O meio eletrônico não interfere na concepção do princípio da imparcialidade, devendo o mediador conduzir indistintamente o procedimento da mediação on-line sem favoritismo, preferência ou preconceito, assegurando que valores e conceitos pessoais não interfiram no resultado do trabalho, auxiliando as partes na condução da plataforma ou site mais adequado para a realização da mediação. A imparcialidade é ter certeza de que o processo está aberto para a entrada das partes, para certificar-se de que nenhuma das partes está em desvantagem em termos de tecnologia.

\section{OS NOVOS PARADIGMAS DA MEDIAÇÃO ON-LINE}

Conforme análise principiológica acima, as implicações da tecnologia não chegam a alterar a natureza da mediação na era digital, impõem-lhe, porém, novos paradigmas. Embora não haja modificação na concepção da mediação on-line, que continua ocorrendo em qualquer tipo de conflito $^{6}$ e sendo utilizada a qualquer tempo - mesmo após já judicializado o conflito ou em fase de execução -, o quarto elemento trazido pela era digital provoca mudanças na comunicação e consequentemente altera a interação entre as partes, exigindo modificações nas relações e nas habilidades do mediador.

A mediação on-line faz parte das mudanças que ocorrem na contemporaneidade, cujas transformações exigem novas ferramentas e consequentes inovações nas formas de interação e nos meios de resolução de conflitos.

Como visto, originalmente, o termo ODR referia-se à resolução de conflitos que surgiam on-line (nomeadamente na configuração de $e$-commerce ou nos fóruns sociais on-line). (KATSH; RIFKIN; GAITENBY, 2000, p. 717). Com o tempo, o uso de tais processos expandiu-se, e as ferramentas e sistemas tecnológicos passaram a ser utilizados para a resolução de disputas tradicionais off-line. Do mesmo modo, as técnicas da mediação off-line também podem ser aplicadas nas resoluções dos conflitos on-line, pois não se alteram pelo uso da tecnologia, podendo ser utilizadas em muitos espaços, isto é, em vários locais de conflito.

Os princípios da mediação tradicional (autonomia, imparcialidade, confidencialidade, oralidade, informalidade e decisão informada) não sofreram alterações, em essência, na mediação on-line, não se podendo, portanto, falar em uma nova espécie de mediação. Mas é indubitável que, por haver mais um elemento decorrente da era digital, seus princípios precisam ser revisitados, principalmente a confidencialidade, a autonomia e a isonomia das partes em razão do acesso e das dificuldades na tecnologia.

O quarto sujeito, que é a tecnologia, sem dúvida provoca mudanças, exigindo readaptações na mediação on-line. A resolução de disputas assistida por tecnologia não é apenas um análogo a um processo face a face, mas provoca mudanças na natureza da interação e nas habilidades necessárias para gerenciar a comunicação e a troca de informações, que podem ter um impacto sobre as partes e os mediadores (RAINEY, 2014, p. 55).

Com efeito, a tecnologia de comunicação é mais um "elemento" no processo da mediação on-line, e sua atuação não pode ser desprezada. É necessário que o mediador informe às partes a

${ }^{6}$ Goodman (2003, p. 14) aponta a impessoalidade como uma grande desvantagem da mediação: "This will address the major claimed disadvantage of cybermediation: that it is impersonal".

Revista de Direito Brasileira | Florianópolis, SC | v. 28 | n. 11 | p.367-386 | Jan./Abr. 2021 
segurança real das informações trocadas em um ambiente digital, de forma que elas possam fazer uma escolha informada sobre os riscos do consentimento. Assegura-se, assim, a confidencialidade, com a comunicação dos riscos e a recomendação do uso de tecnologias mais seguras, cabendo sempre às partes a opção (RAINEY, 2014, p. 39). A autonomia está garantida com a escolha do procedimento sendo feita pelos interessados; além disso, o mediador deve criar um ambiente em que as partes se sintam tratadas em igualdade de condições, com a certeza de que o processo online não as está prejudicando no resultado, assegurando-se a isonomia.

Ao mediador também incumbe o monitoramento do uso da plataforma durante todo o andamento do processo de conflitos. Deve verificar a participação das partes, se alguma delas está participando menos porque tem dificuldades com a plataforma, por exemplo, e até ajustar ou abandonar a tecnologia nesse ponto. A responsabilidade do mediador no que se refere à imparcialidade e à autodeterminação é ter certeza de que nenhuma das partes está em desvantagem tecnológica (RAINEY, 2014, p. 49).

A mediação on-line pode superar as desvantagens dos sistemas judiciais convencionais, principalmente em litígios transfronteiriços, que surgem entre cidadãos de diferentes países (ou diferentes estados dentro de um país) (DEVANESAN; ARESTY, 2012, p. 284), principalmente por ser um meio de solução mais rápido e barato de resolução de litígios (KOVACH; LOVE, 1988, p. 104). Mas, além de oferecer flexibilidade na solução das disputas, assim como todos os métodos de ADR, a mediação on-line incentiva a cooperação das partes na busca de uma solução que as satisfaça, distanciando-se da judicialização do litígio, que tende a fazer com que os interessados mantenham suas posições sem concessões (DEVANESAN; ARESTY, 2012, p. 284).

As vantagens da mediação on-line, no entanto, exigem mudanças na interação e nas habilidades do mediador, pois, além do conhecimento sobre mediação, ele tem de conhecer a tecnologia para a realização da mediação. A competência do mediador está intimamente ligada à criação de confiança - confiança que as partes depositam no mediador. Ora, em grande medida, a confiança é gerada pela capacidade do mediador de demonstrar conhecimento. Deve, portanto, o mediador envolver-se conscienciosamente no autodesenvolvimento relacionado ao uso da tecnologia, antes de apresentar-se ao público como apto para realizar uma mediação on-line (RAINEY, 2014, p. 50)

Vê-se, pois, que a mudança de paradigma na mediação on-line não importa em modificação na função do mediador, que continua, como sempre, a visar, primordialmente, ajudar as partes a acharem uma solução própria (SAMPAIO; BRAGA NETO, 2007, p. 20), mas traz mudanças na natureza da interação e nas habilidades necessárias para gerenciar a comunicação e a troca de informações entre as partes e os mediadores (RAINEY, 2014, p. 55). Exige, sobretudo, modificações nas relações e nas habilidades do mediador, pois, por meio de um diálogo constante entre as ideias e as visões das partes, em ambiente on-line, ele deverá ajudá-las a identificar os resultados que elas realmente querem (KOVACH; LOVE, 1988, p. 104).

A falta de contato pessoal, portanto, não é um obstáculo para a mediação on-line, exigindo apenas uma nova forma de adaptação para a interação entre partes e mediador no meio tecnológico. Devemos buscar novas maneira de lidar com as mudanças introduzidas pela tecnologia de comunicação, assim como nos adaptamos às barreiras da linguagem, da deficiência auditiva, da visão etc.

\section{CONCLUSÃO}

A tecnologia está cada vez mais inserida na vida das pessoas, trazendo uma nova mentalidade e também novos modos de solução on-line de conflitos. Entre os meios adequados de solução de conflitos que ocorrem em ambiente digital, está a mediação on-line, pela qual as partes são as protagonistas da solução, auxiliadas por um terceiro mediador, independente e imparcial, que as estimula a solucionar o conflito. 
A presença de um quarto elemento - a tecnologia - na mediação on-line modifica a forma como as pessoas se comunicam. A tecnologia provocou uma nova forma de comunicação, que exige uma quebra de paradigma para que o mediador possa criar um ambiente acolhedor, propiciando um diálogo e permitindo que as partes construam propostas criativas para a solução do conflito.

A mediação on-line não trouxe uma nova espécie de mediação. A natureza e os princípios da mediação continuam os mesmos. Contudo, embora não se possa falar em um novo tipo de mediação, é indubitável que, por haver mais um elemento decorrente da era digital, seus princípios precisam ser revisitados, em razão do acesso e das dificuldades ligadas à tecnologia: o princípio da confidencialidade exige que os mediadores informem às partes a segurança real das informações trocadas em um ambiente digital, de forma que elas possam fazer uma escolha informada sobre os riscos do consentimento; o princípio da autonomia das partes requer que toda flexibilização no processo de mediação on-line seja marcada por intenso diálogo, cabendo aos interessados a opção pelo procedimento, a escolha da plataforma, do mediador, e até a decisão de retirada do procedimento; segundo o princípio da isonomia das partes, o mediador deve criar um ambiente em que os interessados se sintam tratados em igualdade de condições, com a certeza de que o processo on-line não os está prejudicando no resultado; o princípio da oralidade impõe uma nova forma de adaptação aos meios tecnológicos, como a videoconferência, por exemplo, para a interação entre partes e mediador; o princípio da informalidade permite às partes a opção pelo uso de tecnologia e de suas ferramentas na totalidade ou em parte do processo; o princípio da imparcialidade informa que o mediador deve conduzir o processo sem favoritismos, assegurando que nenhuma das partes fique em desvantagem de tecnologia.

Vê-se, pois, que, embora a mediação on-line não importe em uma nova acepção de mediação, exige mudanças na interação e nas habilidades do mediador, o qual, além do conhecimento sobre mediação, deverá conhecer a tecnologia para a realização da mediação. É necessário, portanto, que o mediador tenha domínio da tecnologia, pois sua competência está ligada também à confiança que nele depositam as partes, que confiam em seu conhecimento sobre a tecnologia.

Assim, a mudança de paradigma na mediação on-line não importa em modificação na função do mediador - que deverá, por meio de um diálogo constante entre as ideias e as visões das partes, em ambiente on-line, ajudá-las a identificar os resultados que elas realmente querem -, mas implica mudanças na natureza da interação e nas habilidades necessárias para gerenciar a comunicação e a troca de informações entre as partes e os mediadores, o que exige, sobretudo, modificações nas relações e nas habilidades do mediador.

\section{REFERÊNCIAS}

ALMEIDA, Diogo Assumpção Rezende de; PANTOJA, Fernanda Medina; ANDRADE, Juliana Loss de. Fundamentos. In: HALE, Durval; PINHO, Humberto Dalla Bernardina de; CABRAL, Trícia Navarro Xavier (org.). O marco legal da mediação no Brasil: comentários à Lei n. ${ }^{\circ}$ 13.140, de 26 de junho de 2015. São Paulo: Atlas, 2016. p. 35-90.

ALMEIDA, Tania. Mediação e conciliação: dois paradigmas distintos, duas práticas diversas. In: SOUZA, Luciane Moessa de (coord.). Mediação de conflitos: novo paradigma de acesso à justiça. Santa Cruz do Sul: Essere nel Mondo, 2015. p. 85-94.

AMERICAN ARBITRATION ASSOCIATION; AMERICAN BAR ASSOCIATION'S SECTION OF DISPUTE RESOLUTION; ASSOCIATION FOR CONFLICT RESOLUTION. Model standards of conduct for mediators. 2005. Disponível em: 
https://www.americanbar.org/content/dam/aba/migrated/2011_build/dispute_resolution/model_st andards_conduct_april2007.authcheckdam.pdf. Acesso em: 3 jan. 2019.

AMORIM, Fernando Sérgio Tenório de. A resolução online de litígios (ODR) de baixa intensidade: perspectivas para a ordem jurídica brasileira. Pensar: Revista de Ciências Jurídicas, Fortaleza, v. 22, n. 2, p. 514-539, maio/ago. 2017. Disponível em: http://periodicos.unifor.br/rpen/article/view/5397/pdf. Acesso em: 4 jan. 2019.

ARBIX, Daniel do Amaral. Resolução online de controvérsias. São Paulo: Intelecto Editora, 2017.

CAHALI, Francisco José. Curso de arbitragem. 2. ed. São Paulo: Revista dos Tribunais, 2012.

CAMPBELL, Ray Worthy. The end of law schools: legal education in the era of legal services business. Mississippi Law Journal, [s.l.], v. 85, p. 1-97, 2016. Disponível em: http://mississippilawjournal.org/wp-content/uploads/2017/03/1.-Campbell.pdf. Acesso em: 3 jan. 2019.

DEVANESAN, Ruha; ARESTY, Jeffrey. ODR and Justice: an evaluation of online dispute resolution's interplay with traditional theories of justice. In: ABDEL WAHAB, Mohamed S.; KATSH, Ethan; RAINEY, Daniel (ed.). Online dispute resolution: theory and practice: a treatise on technology and dispute resolution. The Hague: Eleven International Pub., 2012. p. 263-305.

EISEN, Joel B. Are we ready for mediation in cyberspace? BYU Law Review, [s.l.], n. 4, p. 1305-1360, 1998. Disponível em: https://digitalcommons.law.byu.edu/lawreview/vol1998/iss4/1. Acesso em: 4 jan. 2019.

FRIEDMAN, Bruce A. Online mediation - Press delete. Set. 2013. Disponível em: $\mathrm{http} / / /$ friedmanmediation.com/mediation/online-mediation-press-delete-2/. Acesso em: 4 jan. 2019.

GOODMAN, Joseph W. The pros and cons of online dispute resolution: an assessment of cybermediation websites. Duke Law \& Technology Review, [s.l.], v. 2, p. 1-16, 2003. Disponível em: https://scholarship.law.duke.edu/cgi/viewcontent.cgi?article=1073\&context=dltr. Acesso em: 4 jan. 2019.

HANG, Lan Q. Online dispute resolution systems: the future of cyberspace law. Santa Clara Law Review, [s.l.], v. 41, n. 3, p. 837-866, 2001. Disponível em: https://digitalcommons.law.scu.edu/lawreview/vol41/iss3/4/. Acesso em: 4 jan. 2019.

HAYNES, John M.; MARODIN, Marilene. Fundamentos da mediação familiar. Porto Alegre: Artes Médicas, 1996.

HOGAN LOVELLS PUBLICATIONS. The future of arbitration: New technologies are making a big impact - and AI robots may take on "human" roles. Fev. 2018. Disponível em:

https://www.hoganlovells.com/en/publications/the-future-of-arbitration-ai-robots-may-take-onhuman-roles. Acesso em: 3 jan. 2019.

INTERNATIONAL CHAMBER OF COMMERCE. Three takeaways on how digital technologies are transforming arbitration. Paris, 2017. Disponível em: https://iccwbo.org/media- 
wall/news-speeches/three-takeaways-digital-technologies-transforming-arbitration/. Acesso em: 3 jan. 2019.

JAMS MEDIATION, ARBITRATION AND ADR SERVICES. Mediators ethics guidelines. [20-?]. Disponível em: https://www.jamsadr.com/mediators-ethics/. Acesso em: 3 jan. 2019.

KATSH, Ethan. Dispute resolution in cyberspace. Connecticut Law Review, [s.l.], n. 28, p. 953971, 1996. Disponível em: http://www.umass.edu/legal/articles/uconn.html. Acesso em: 4 jan. 2019.

KATSH, Ethan; RIFKIN, Janet; GAITENBY, Alan. E-commerce, e-disputes, and e-dispute resolution: in the shadow of "eBay Law". Ohio State Journal on Dispute Resolution, [s.l.], v. 15, n. 3, p. 705-734, 2000. Disponível em: https://www.umass.edu/cyber/katsh.pdf. Acesso em: 4 jan. 2019.

KOVACH, Kimberlee K.; LOVE, Lela P. Mapping mediation: The risks of Riskin's Grid. Harvard Negotiation Law Review, [s.l.], v. 3, n. 71, p. 71-110, 1988. Disponível em: https://papers.ssrn.com/sol3/papers.cfm?abstract_id=2350957. Acesso em: 3 jan. 2019.

LIDE, E. Casey. ADR and cyberspace: the role of alternative dispute resolution in online commerce, intellectual property and defamation. Ohio State Journal on Dispute Resolution, [s.l.], v. 12, n. 1, p. 193-222, 1996. Disponível em: https://kb.osu.edu/bitstream/handle/1811/79766/OSJDR_V12N1_193.pdf?sequence=1. Acesso em: 4 jan. 2019.

MELAMED, Jim. Divorce mediation and the Internet. 2002. Disponível em: http://www.mediate.com/articles/melamed9.cfm. Acesso em: 4 jan. 2019.

MELAMED, Jim; HELIE, John. The WWW main street of the future is here today. 1999. Disponível em: http://www.mediate.com/articles/jimmjohn.cfm\#. Acesso em: 4 jan. 2019.

MIRANDA NETTO, Fernando Gama de; SOARES, Irineu Carvalho de Oliveira. Princípios procedimentais no novo Código de Processo Civil. In: ALMEIDA, Diogo Assumpção Rezende de; PANTOJA, Fernanda Medina; PELAJO, Samantha (coord.). A mediação no Novo Código de Processo Civil. 2. ed. Rio de Janeiro: GenForense, 2016. p. 109-120.

PEIXOTO, Ravi. Os "princípios” da mediação e conciliação. In: ZANETI JUNIOR, Hermes; CABRAL, Trícia Navarro Xavier (coord.). Justiça Multiportas: mediação, conciliação, arbitragem e outros meios adequados de solução de conflitos. 2. ed. Salvador: JusPodivm, 2018. p. 91-107.

PHILIPPE, Mirèze. ODR redress system for consumer disputes: clarifications, UNCITRAL works \& EU regulation on ODR. International Journal of Online Dispute Resolution, [s.l.], v. 1, n. 1, p. 57-69, 2014. Disponível em:

https://www.elevenjournals.com/tijdschrift/ijodr/2014/1/IJODR_2014_001_001_004.pdf. Acesso em: 4 jan. 2019.

RABINOVICH-EINY, Orna. Technology's impact: the quest for a new paradigm for accountability in mediation. Harvard Negotiation Law Review, [s.l.], v. 11, p. 253-293, 2006. Disponível em: 
https://pdfs.semanticscholar.org/6566/170a1691f80c846c4240e285786cb8a2d493.pdf. Acesso em: 4 jan. 2019.

RABINOVICH-EINY, Orna; KATSH, Ethan. Digital justice: reshaping boundaries in an online dispute resolution environment. International Journal of Online Dispute Resolution, [s.l.], v. 1, n. 1, p. 5-36, 2014. Disponível em:

https://heinonline.org/HOL/LandingPage?handle=hein.journals/ijodr1\&div=6\&id=\&page=. Acesso em: 4 jan. 2019.

RAINEY, Daniel. Third-party ethics in the age of the fourth party. International Journal of Online Dispute Resolution, [s.l.], v. 1, n. 1, p. 37-56, 2014. Disponível em: https://www.elevenjournals.com/tijdschrift/ijodr/2014/1/IJODR_2014_001_001_003. Acesso em: 3 jan. 2019.

RAINIE, Lee; WELLMAN, Barry. Networked: the new social operating system. Cambridge, MA: MIT Press, 2012.

RAYMOND, Anjanette H.; SHACKELFORD, Scott J. Technology, ethics, and access to justice: should an algorithm be deciding your case. Michigan Journal of International Law, [s.l.], v. 35, n. 3, p. 485-524, 2013. Disponível em: http://www.mjilonline.org/wordpress/wpcontent/uploads/2015/04/35-3_Technology-Ethics-and-Access-to-Justice-Should-an-Alogrithmbe.pdf. Acesso em: 5 jan. 2019.

SAMPAIO, Lia Regina; BRAGA NETO, Adolfo. O que é mediação de conflitos. São Paulo: Brasiliense, 2007.

SANTANNA, Ana Carolina Squadri; VERAS, Cristina Vianna; MARQUES, Giselle Picorelli Yacoub. Independência e imparcialidade: princípios fundamentais da mediação. In: ALMEIDA, Diogo Assumpção Rezende de; PANTOJA, Fernanda Medina; PELAJO, Samantha (coord.). A mediação no Novo Código de Processo Civil. 2. ed. Rio de Janeiro: GenForense, 2016. p. 45-69.

TARTUCE, Fernanda. Mediação nos conflitos civis. 5. ed. São Paulo: Método, 2015.

UNITED NATIONS COMMISSION ON INTERNATIONAL TRADE LAW. A/CN.9/WG.III/WP.123: Online dispute resolution for cross-border electronic commerce transactions: draft procedural rules. Working Group III (Online dispute resolution). Twentyeighth session. Viena, 18-22 nov. 2013. Disponível em:

<www.uncitral.org/uncitral/commission/working_groups/3Online_Dispute_Resolution.html. Acesso em: 3 an. 2019.

WANDERLEY, Waldo. Mediação. Brasília, DF: MSD, 2004.

WARAT, Luis Alberto. O ofício do mediador. Florianópolis: Habitus, 2001. 